Antoine Lavoisier, born in France in 1734, was carefully educated and, having amplemeans, devoted himself to science. His most important work was begun in 1770, and continued until his death on the guillotine in 1794, when he suffered the penalty of a Fermier général, or tax collector, although he had discharged this office honourably and honestly, as well as doing much important work in the service of the State.

Lavoisier learned of the isolation of oxygen in 1774 from Priestley himself in Paris, and soon saw that it was a part of the air concerned with combustion and calcination, which resulted from a combination of oxygen with the combustible or metal, and not from a loss of phlogiston. In the course of further work, he confirmed this conclusion, which he stated fully in 1783.

Since non-metals such as sulphur, phosphorus and carbon, on combustion in oxygen, form acids, Lavoisier proposed the name principe oxigine, from the Greek meaning 'producer of acids'. He drew up a list of elements, these being substances which, so far, had not been divided by chemical processes into any simpler bodies, and in 1789 he published his famous text-book, "Traité Elémentaire de Chimie". In this he describes an experiment in which mercury is heated in a confined volume of air, when it slowly takes up oxygen to form some red oxide, and the air contracts to a limiting volume. On heating the red oxide, oxygen is evolved, in volume equal to the contraction suffered by the air. Lavoisier also showed that oxygen is absorbed in the blood in respiration, as Mayow suspected, and carbon dioxide evolved, the oxidation of material containing carbon being the source of animal heat. With Lavoisier, chemistry entered its modern phase. Only one further step remained, and this was taken by John Dalton by the introduction of the atomic theory.

The atomic theory goes back to the old Greek philosopher Demokritos, about 450 B.c., was revived in the Epicurean philosophy, and made into a poem by Lucretius. It was never lost sight of, but was notably revived by Gassend early in the seventeenth century. Newton made extensive use of it, and an early application to chemistry was by William Higgins in 1789, who recognized that combination occurs in multiple proportions by successive addition of $1,2,3$, etc., particles of one element, say oxygen, to one particle of another, say nitrogen. Higgins's work was appreciatively mentioned by Davy. Richter, in Germany, from 1791, had introduced the idea of combining weights.

John Dalton was born in 1766 in Cumberland, his parents being Quakers, to which society he himself belonged. His circumstances were modest, and he supported himself all his life by teaching, being appointed professor of mathematics and natural philosophy in New College, Manchester, in 1793. The College later moved to York, but Dalton remained in Manchester, earning his living as a private tutor, until his death in 1844. One of his pupils was the great physicist Joule. Dalton's main characteristics were plainness, modesty, and perseverance, united to genius.

Dalton's atomic theory arose from the influence of Newton, whose writings he had carefully studied. $\mathrm{He}$ took from Newton the theory that a gas exerts a pressure because of repulsive forces between its particles, the latter being at rest. The kinetic theory, postulating that pressure is due to bombardment by moving particles, although proposed by Bernoulli in 1738, had dropped out of sight. Dalton supposed that the repulsion was due to atmospheres of heat, which Lavoisier supposed was an imponderable material element called 'caloric', surrounding the material atoms.

In 1801-2, Dalton read several important papers to the Manchester Literary and Philosophical Society, describing the law of partial pressures, the solubilities of mixed gases, and the vapour pressures of liquids; and in 1803 he read a paper on "The Proportions of the Several Gases or Elastic Fluids Constituting the Atmosphere", to which, when it was first printed in 1805 , the first table of atomic weights had, in the interval, been added. He was in possession of this theory before 1804, since in August of that year he explained it to Thomas Thomson, who published an account of it in 1807 . The theory, and atomic symbols, are used in Dalton's notebooks of 1803 .

Dalton seems to have been led to the atomic theory on physical grounds in attempts to explain the properties of mixed gases. He calculated the relative weights of the atoms, taking the weight of the lightest atom, that of hydrogen, as 1 . In order to do this, he made assumptions about the numbers of atoms combining; for example, he supposed that water contains one atom each of hydrogen and oxygen, whereas we now know that it contains two of hydrogen and one of oxygen. The theory explained the facts of ohemical combination, including the law of multiple proportions, and the results found by Richter. Dalton's theory was first made known by Thomas Thomson, professor at Glasgow, who gave an account of it in his "System of Chemistry" in 1807. The first volume of Dalton's "New System of Chemical Philosophy" appeared in 1808. Dalton used curious symbols, that for hydrogen being 0 , like the Bohr atom; the modern chemical symbols were introduced by Berzelius in 1813.

Dalton's atomic theory is the great guiding prin. ciple of modern chemistry. It has suffered slight modification, since all the atoms of a given element are not of identical weight, as Dalton thought; and also, as Newton suspected, it has proved possible to divide atoms experimentally into simpler parts, so that the atoms are formed of a small number of primary particles, and the artificial transmutation of elements is now a fact. If anything, however, the atoms have become more real than they were even for Dalton, who saw them elearly in the eye of the mind.

With Dalton, chemistry had become a modern science, and a history of alchemy and early chemistry ends ; he brought the science to the beginning of the road it has followed ever since.

\section{EARTH MOVEMENT RESULTING FROM AN ATOMIC BOMB EXPLOSION}

$I^{1}$ N 1904, Horace Lamb published ${ }^{1}$ solutions of elastic wave equations, and predicted the wave pattern at a distant point from waves generated by an impulsive force applied vertically at the earth's surface. From this work he suggested that the general to-and-fro movement characteristic of a seismogram might be due either to a succession of primitive shocks or to instrumental imperfections.

On Monday, July 16, 1945, Lamb's conditions of a single initial vertical ground impulse were met 
experimentally for the first time at the test of the atomic bomb in Jornada del Muerto Valley, New Mexico. On that occasion the source of the earth tremors was a simple single instantaneous vertical impact on the ground produced by the explosion of an atomic bomb $100 \mathrm{ft}$. above the surface. There was no succession of primitive shocks to explain unpredicted oscillations, and the three-component Loet seismograph orientated in three mutually perpendicular directions, $(a)$ horizontally from point of observation to point of explosion, $(b)$ horizontally at right angles to $(a)$, and (c) vertical, was magnetically damped about $0 \cdot 7$ critical, so there was no question of instrumental self-oseillation. The magnitude of the ground vibrations has not yet been made public, but the qualitative analysis of the records has just been published by L. Don Leet ${ }^{2}$.

The seismograms showed continuous oscillation. The first waves to arrive were $P_{2}$, refracted compressional waves, on the longitudinal and vertical seismograms, followed by $S_{2}$, refracted shear waves, on the transverse seismogram. After these came the $P_{1}$, direct compressional waves on the longitudinal and vertical components. Coupled waves on all components succeeded these, and were followed by $H$, hydrodynamic waves, on the longitudinal and vertical components. Surface shear waves arrived at the point of observation shortly afterwards and were recorded on the transverse seismogram. The latter ones of these were accompanied by horizontally polarized surface compressional waves on the longitudinal seismogram. The remaining part of the seismograms had Rayleigh waves on the longitudinal and vertical components and surface shear waves on the transverse seismogram.

$P_{2}$ was the standard bodily compressional wave. Leet states that from its angle of emergence as well as its velocity, the wave must have been refracted through material capable of transmitting waves of higher velocity than the surface layer could. $P_{1}$ travelled through the earth's surface layer. $S_{2}$ was an independent transverse wave assumed to have been a refracted body wave because of its velocity and period. Leet noted transverse motion from the very beginning of the record. $C$ has been called the coupled wave. It was not predicted by standard elasticity theory, but was observed by Leet in $1939^{3}$. The diagnostic characteristic of this wave is that a particle in its path moves along the diagonal of a rectangular frame facing in the longitudinal direction. This results in simultaneous maxima and minima on all three components of the seismograph registrations. A novel feature of this wave on the atomic bomb record was that it was twinned. There was a $C$ wave of period 0.4 sec. arriving at the same time and co-existing with one of period about 1.0 sec. The motion of a particle was left up push - right down pull. $Q$, the surface shear wave, arrived on the transverse component just as $C$ was dying out. $H$, the hydrodynamic wave, was new to seismology. The wave caused a particle in its path to move in a longitudinal-vertical plane, clearly independent of motion on the transverse component at the same time. Leet states that the unique and significant thing about the $H$ motion is that it is the opposite of that of the Rayleigh wave, and the particle at the top of its inclined elliptical orbit moves forward as for a wave on water. $\mathrm{He}_{e}$ is of the opinion that it seems reasonable to attribute the existence of the $H$ wave to special properties of the material at the surface of the Jornada del Muerto Valley, namely, alluvial sands and gravels. A similar wave has been observed by Leet from a small dynamite shot in an area having a surface layer of sand $55 \mathrm{ft}$. thick underlain by clay $165 \mathrm{ft}$. thick. In both cases the horizontal component of $H$ dominated the vertical, and the major axis of the elliptical path was inclined at an acute angle to the horizontal plane. $R$, the Rayleigh wave, caused particle movement in an elliptic orbit with the minor axis longitudinal and the major axis vertical. At the top of its elliptical orbit, the particle moved towards the source. The vertical component was larger relative to the horizontal than for $H$, but not in the classical ratio of vertical : horizontal $=1.5: 1$. The coupled wave carried an appreciable portion of the energy in the ground waves, and the hydrodynamic wave produced the greatest displacements on the record.

Leet's paper represents an important advance towards the solution of the seismological problem of establishing observationally the types of waves which can be supported by earth materials in their natural position.

2Phil. Trans. Roy. Soc., A, 203, 1 (1904).

-Leet, L. Don, "Earth Motion from the Atomic Bomb Test", American Scientist, 34, No. 2 (1946).

${ }^{3}$ Leet, L. Don, Bull. Seis. Soc. Amer., 29, 487 (1939).

\section{RELATIONSHIP BETWEEN STRUCTURE AND ACTION IN DRUGS WITH CURARIFORM ACTIONS}

\author{
By P. E. B. HOLMES, D. J. JENDEN \\ AND

\section{DR. D. B. TAYLOR} \\ Departments of Physiology and Pharmacology, \\ King's College, London
}

TNG and Wright ${ }^{1,2}$, in two comprehensive papers, 1 presented the results of the measurement of the curariform activity of an extensive series of onium salts. Later, Ing ${ }^{3}$ reviewed the literature up to 1936. Since that time much interesting work on the subject has appeared, the three papers by Raventos ${ }^{4}$, Clark and Raventos ${ }^{8}$ and Raventos ${ }^{8}$ being of special interest from the theoretical point of view.

We can start with a consideration of the differences between the structure of the ammonium ion according to the classical theory of valency and the structure of the same ion according to quantum mechanics. Classical theory assigned the structure<smiles>[NH3+]</smiles>

to the ammonium ion, and tacitly assumed the charge to be localized to the nitrogen atom. The development of quantum mechanics has, however, led to a reconsideration of this structure, and Pauling ${ }^{7}$ has pointed out that resonance between ionic and covalent bonds of the type $A-B \rightleftharpoons A^{+} B^{-}$will result in a distribution of the positive charge in the ammonium ion. $\mathrm{He}$ points out that sixteen structures have to be considered, one completely covalent structure 